\title{
The Association of Team-Specific Workload and Staffing with Odds of Burnout Among VA Primary Care Team Members
}

\author{
Christian D. Helfrich, MPH, $P h D^{1,2}$, Joseph A. Simonetti, MD, MPH ${ }^{1,3}$, Walter L. Clinton, $P h D^{4}$, \\ Gordon B. Wood, MS ${ }^{4}$, Leslie Taylor, PhD', Gordon Schectman, MD', Richard Stark, MD', \\ Lisa V. Rubenstein, MD ${ }^{7,8,9}$, Stephan D. Fihn, MD, MPH ${ }^{1,3,4}$, and Karin M. Nelson, MD, MSHS
}

\begin{abstract}
'Seattle-Denver Center of Innovation for Veteran-Centered and Value-Driven Care VA Puget Sound Puget Sound Health Care System, US Department of Veterans Affairs, Seattle, WA, USA; ${ }^{2}$ Department of Health Services, University of Washington School of Public Health, Seattle, WA, USA; ${ }^{3}$ Department of Medicine, University of Washington School of Medicine, Seattle, WA, USA; ${ }^{4}$ Office of Analytics and Business Intelligence, US Department of Veterans Affairs, Seattle, WA, USA; ${ }^{5}$ VA Office of Patient Care Services, Washington, DC, USA; ${ }^{6}$ VA Office of Clinical Operations, Washington, DC, USA; 7 Center for the Study of Healthcare Innovation, Implementation, \& Policy, Greater Los Angeles VA, Sepulveda, CA, USA; ${ }^{8}$ UCLA School of Medicine, Los Angeles, CA, USA; ${ }^{9}$ RAND Corp, Santa Monica, CA, USA.
\end{abstract}

BACKGROUND: Work-related burnout is common in primary care and is associated with worse patient safety, patient satisfaction, and employee mental health. Workload, staffing stability, and team completeness may be drivers of burnout. However, few studies have assessed these associations at the team level, and fewer still include members of the team beyond physicians.

OBJECTIVE: To study the associations of burnout among primary care providers (PCPs), nurse care managers, clinical associates (MAs, LPNs), and administrative clerks with the staffing and workload on their teams.

DESIGN: We conducted an individual-level cross-sectional analysis of survey and administrative data in 2014.

PARTICIPANTS: Primary care personnel at VA clinics responding to a national survey.

MAIN MEASURES: Burnout was measured with a validated single-item survey measure dichotomized to indicate the presence of burnout. The independent variables were survey measures of team staffing (having a fully staffed team, serving on multiple teams, and turnover on the team), and workload both from survey items (working extended hours), and administrative data (patient panel overcapacity and average panel comorbidity).

KEY RESULTS: There were 4610 respondents (estimated response rate of $20.9 \%$ ). The overall prevalence of burnout was $41 \%$. In adjusted analyses, the strongest associations with burnout were having a fully staffed team (odds ratio $[\mathrm{OR}]=0.55,95 \%$ CI $0.47-0.65$ ), having turnover on the team $(\mathrm{OR}=1.67$, 95\% CI $1.43-$ 1.94), and having patient panel overcapacity (OR= 1.19 , 95\% CI 1.01-1.40). The observed burnout prevalence was $30.1 \%$ lower (28.5\% vs. $58.6 \%$ ) for respondents working on fully staffed teams with no turnover and caring for a panel within capacity, relative to respondents in the inverse condition.

Electronic supplementary material The online version of this article (doi:10.1007/s11606-017-4011-4) contains supplementary material, which is available to authorized users.

Received July 26, 2016

Revised January 11, 2017

Accepted February 2, 2017

Published online February 23, 2017
CONCLUSIONS: Complete team staffing, turnover among team members, and panel overcapacity had strong, cumulative associations with burnout. Further research is needed to understand whether improvements in these factors would lower burnout.

KEY WORDS: burnout; primary care staffing; team-based care; primary care workload; patient-centered medical home.

J Gen Intern Med 32(7):760-6

DOI: $10.1007 / \mathrm{s} 11606-017-4011-4$

(C) Society of General Internal Medicine 2017

\section{INTRODUCTION}

Burnout is a prevalent occupational condition characterized by employee feelings of emotional exhaustion, lack of personal connection to colleagues and patients, and doubting their professional abilities or impact. ${ }^{1}$ Over half of US physicians ${ }^{2}$ and nearly half of nurses working in primary care ${ }^{3,4}$ screen positive for burnout on surveys. National surveys of US physicians and Veterans Health Administration (VA) primary care employees report that burnout has increased significantly in recent years. 2,5

Clinician burnout has many negative consequences. Patients cared for by providers suffering from burnout report lower satisfaction $^{6,7}$ and receive lower-quality care. ${ }^{8-10}$ Providers with burnout report higher levels of absenteeism and more frequent intention to leave their jobs. ${ }^{11-13}$ Ultimately, they are more likely to reduce work hours ${ }^{14}$ and leave medical practice entirely. $^{12,15,16}$ This has led some to call for the Triple Aim advanced by the Institute for Healthcare Improvement to be amended to include a fourth aim of improving clinician work life in addition to the original three goals of improving patient experience, expanding population health, and reducing costs. ${ }^{17}$

A number of workplace conditions appear to contribute to burnout. Workload issues such as working overtime ${ }^{18,19}$ and excess patient volume $\mathrm{e}^{20-22}$ are associated with burnout in primary care, as are turnover among primary care support staff $^{20}$ and insufficient staff to manage patient volume. ${ }^{23-26}$

The patient-centered medical home (PCMH) has been suggested as a model to simultaneously improve quality of care 
and reduce burnout among primary care employees in part through team-based approaches to patient care. ${ }^{27}$ Modern primary care is complex, involving the provision and coordination of care for patients who often have several chronic medical and psychiatric conditions and who require a variety of services from multiple providers. Team-based care should distribute clinical duties among team members in a way that optimally matches team members' responsibilities and competencies.

In 2010, the US Department of Veterans Affairs undertook the largest implementation of the PCMH to date, involving over 900 primary care clinics. ${ }^{28}$ A key feature of the VA's implementation of this model was the creation of Patient Aligned Care Teams (PACT) consisting of one primary care provider, one nurse $(\mathrm{RN})$ care manager, one clinical associate (LPN), and one clerical assistant. Given the scale of program, however, it proved difficult to achieve full staffing at all sites. Moreover, demand for care varied among sites resulting in variable workload.

In prior evaluations of the PACT initiative, no associations were found between burnout among primary care personnel and clinical workload in terms of primary care team panel size or the complexity of patients on the panel. ${ }^{29,}{ }^{30}$ However, these evaluations adjusted for panel size and complexity only at the clinic level, a method that may mask important variation in workload experienced at the team level. While the perception of inadequate staffing was associated with burnout, ${ }^{29,} 31$ the importance of team-specific employee turnover was not evaluated. Finally, while prior research has demonstrated that workload and staffing are associated with burnout in primary care, little is known about the individual or combined effects of excess workload and inadequate staffing. We sought to assess the association between burnout among primary care employees and team-specific staffing and workload, as well as staffing and workload among each of the four occupations that constitute the core VA medical home team.

\section{METHODS}

\section{Setting and Design}

We conducted an individual-level cross-sectional analysis of national VA primary care personnel survey data collected from members of patient aligned care teams, and administrative data on primary care team workload. The survey was fielded online in August and September 2014. The survey link was disseminated via an email from VA central office leadership to network and facility leaders, with instructions to distribute to primary care personnel.

\section{Measures and Sample}

We included respondents from four occupations that make up the core VA primary care team: primary care providers (PCPs, which included physicians, nurse practitioners, and physician assistants), nurse care managers, clinical associates (mainly licensed practical nurses), and administrative clerks.

Workplace burnout was measured with a validated singleitem measure used in the Physician Worklife Study that asks respondents to rate their level of burnout using a five-point ordinal scale (Table 1). We dichotomized burnout as $\geq 3$ (burnout) versus $<3$ (not burned out) according to previously established cutoffs. ${ }^{32}$

We analyzed nine independent variables: three related to team staffing and six related to clinical workload. We anticipated that belonging to a single, stable, fully staffed team would, on average, improve the working environment, and reduce burnout. Team staffing variables included three survey items: Are you currently on more than one team?; Is your team currently staffed at the recommended 3:1 ratio? (3 full-time staff for 1 full-time PCP); and Has your team had any changes in, or loss of, staff in the past 12 months?

We anticipated that high workload, represented by panel overcapacity, patient appointments outside regular hours, and a panel of patients with high comorbidities, would contribute to a more stressful work environment and higher burnout. Workload variables included four survey items and two variables from administrative data. The three survey items were questions asked only of respondents who replied yes to the question Does your PACT team have provider appointments available outside the traditional business hours of $M-F, 0800$ 1700 (8 am-5 pm)? We refer to this as extended hours. This subgroup was asked: How often does your team work extended hours during the week? (4 categories dichotomized to Yes/ No); How often does your team work extended hours on the weekends? (4 categories dichotomized to Yes/No); and Does your team work extended hours together as a team (at least $80 \%$ of the time)? (Yes/No).

The administrative variables were two team-level clinic workload measures that we linked to individual respondents. The first was the size of the patient panel for the respondent's team, dichotomized as within or over capacity. We defined panel capacity based on a national VA recommendation of 1200 patients per panel, adjusted for the number of half-days per week providers spend providing primary care and for provider type, with nurse practitioners and physician assistants having lower panel targets of 900 patients. ${ }^{28}$ Second, we calculated panel comorbidity, using the average Gagne comorbidity score, a validated, single-number comorbidity score that combines the conditions in the Charlson and Elixhauser measures to predict short- and long-term mortality. ${ }^{33}$

We excluded respondents who did not know whether their team was currently staffed at the recommended 3:1 ratio $(n=$ 385 ), or who could not be linked to a team in the administrative files and therefore for whom no data on panel size or patient comorbidity were available $(n=239)$.

Other covariates included duration of VHA tenure (8 categories), total years/time working in the PACT model (4 categories), and clinic location (community-based outpatient clinic [CBOC] or VA medical center [VAMC]). 
Table 1 Descriptive Statistics

\begin{tabular}{|c|c|c|c|c|c|}
\hline Variable & $\begin{array}{l}\text { All roles } \\
(n=4610)\end{array}$ & $\begin{array}{l}\mathrm{PCP} \\
(n=1517,32.9 \%)\end{array}$ & $\begin{array}{l}\text { Nurse } \\
(n=1276,27.7 \%)\end{array}$ & $\begin{array}{l}\text { CA } \\
(n=1164,25.2 \%)\end{array}$ & $\begin{array}{l}\mathrm{AC} \\
(n=653,14.2 \%)\end{array}$ \\
\hline \multicolumn{6}{|l|}{ Burnout, no. (\%) } \\
\hline \multicolumn{6}{|l|}{ Physician Worklife Study index } \\
\hline 1 = I enjoy my work... & $881(19.1 \%)$ & $199(13.1 \%)$ & $212(16.6 \%)$ & $317(27.2 \%)$ & $153(23.4 \%)$ \\
\hline $2=$ Occasionally $\ldots$ & $1847(40.1 \%)$ & $571(37.6 \%)$ & $534(41.8 \%)$ & $475(40.8 \%)$ & $267(40.9 \%)$ \\
\hline $3=\mathrm{I}$ am definitely.. & $1093(23.7 \%)$ & $429(28.3 \%)$ & $310(24.3 \%)$ & $232(19.9 \%)$ & $122(18.7 \%)$ \\
\hline $4=$ The symptoms.. & $496(10.76 \%)$ & $217(14.3 \%)$ & $135(10.6 \%)$ & $88(7.6 \%)$ & $56(8.6 \%)$ \\
\hline $5=$ I feel completely burned... & $293(6.36 \%)$ & $101(6.7 \%)$ & $85(6.7 \%)$ & $52(4.5 \%)$ & $55(8.4 \%)$ \\
\hline VA medical center (vs. CBOC), no. (\%) & $2170(47.1 \%)$ & $798(52.6 \%)$ & $587(46.0 \%)$ & $492(42.3 \%)$ & $293(44.9 \%)$ \\
\hline \multicolumn{6}{|l|}{ Tenure with VA, no. (\%) } \\
\hline$<6$ months & $168(3.6 \%)$ & $58(3.8 \%)$ & $37(2.9 \%)$ & $41(3.5 \%)$ & $32(4.9 \%)$ \\
\hline 6-12 months & $282(6.1 \%)$ & $78(5.1 \%)$ & $70(5.5 \%)$ & $83(7.1 \%)$ & $51(7.8 \%)$ \\
\hline $1-2$ years & $494(10.7 \%)$ & $132(8.7 \%)$ & $123(9.6 \%)$ & $139(11.9 \%)$ & $100(15.3 \%)$ \\
\hline $3-5$ years & $1028(22.3 \%)$ & $297(19.6 \%)$ & $288(22.6 \%)$ & $279(24.0 \%)$ & $164(25.1 \%)$ \\
\hline $5-10$ years & $1140(24.7 \%)$ & $376(24.8 \%)$ & $313(24.5 \%)$ & $295(25.3 \%)$ & $156(23.9 \%)$ \\
\hline $10-15$ years & $677(14.7 \%)$ & $283(18.7 \%)$ & $173(13.6 \%)$ & $157(13.5 \%)$ & $64(9.8 \%)$ \\
\hline $15-20$ years & $295(6.4 \%)$ & $115(7.6 \%)$ & $85(6.7 \%)$ & $59(5.1 \%)$ & $36(6.4 \%)$ \\
\hline$>20$ years & $526(11.4 \%)$ & $178(11.7 \%)$ & $187(14.7 \%)$ & $111(9.5 \%)$ & $50(7.7 \%)$ \\
\hline \multicolumn{6}{|l|}{ Experience with PACT, no. (\%) } \\
\hline$<6$ months & $325(7.1 \%)$ & $83(5.5 \%)$ & $95(7.4 \%)$ & $79(6.8 \%)$ & $68(10.4 \%)$ \\
\hline 6-12 months & $486(10.5 \%)$ & $116(7.6 \%)$ & $133(10.4 \%)$ & $140(12.0 \%)$ & $97(14.8 \%)$ \\
\hline $1-2$ years & $1148(24.9 \%)$ & $341(22.5 \%)$ & $290(22.7 \%)$ & $309(26.6 \%)$ & $208(31.8 \%)$ \\
\hline$>2$ years & $2651(57.5 \%)$ & $977(64.4 \%)$ & $758(59.4 \%)$ & $636(54.6 \%)$ & $280(42.9 \%)$ \\
\hline Fully staffed & $2740(64.8 \%)$ & $783(57.4 \%)$ & $750(62.4 \%)$ & $753(69.5 \%)$ & $454(77.7 \%)$ \\
\hline Turnover & $2821(61.2 \%)$ & $939(61.9 \%)$ & $828(64.9 \%)$ & $684(58.8 \%)$ & $370(56.7 \%)$ \\
\hline Member of multiple teams & $1241(26.9 \%)$ & $212(14.0 \%)$ & $419(32.8 \%)$ & $327(28.1 \%)$ & $283(43.3 \%)$ \\
\hline \multicolumn{6}{|l|}{ Clinic workload and capacity, no. (\%) } \\
\hline Panel overcapacity & $1371(31.6 \%)$ & $471(33.2 \%)$ & $354(29.6 \%)$ & $368(33.3 \%)$ & $178(28.9 \%)$ \\
\hline Average panel comorbidity (mean, SD) & $0.444(0.304)$ & $0.477(.341)$ & $0.429(0.268)$ & $0.420(0.297)$ & $0.439(0.288)$ \\
\hline Works extended hours & $1719(37.3 \%)$ & $643(42.4 \%)$ & $480(37.6 \%)$ & $385(33.1 \%)$ & $211(32.3 \%)$ \\
\hline \multicolumn{6}{|c|}{ Extended-hours clinic workload among subgroup that work extended hours $N=1719$} \\
\hline & $\begin{array}{l}\text { All Roles } \\
(n=1719)\end{array}$ & $\begin{array}{l}\text { PCP } \\
(n=643,37.4 \%)\end{array}$ & $\begin{array}{l}\text { Nurses } \\
(n=480,27.92 \%)\end{array}$ & $\begin{array}{l}\mathrm{CA} \\
(n=385,22.4 \%)\end{array}$ & $\begin{array}{l}\mathrm{AC} \\
(n=211,12.3 \%)\end{array}$ \\
\hline Works extended hours during week & $1538(89.5 \%)$ & $573(89.0 \%)$ & $438(91.2 \%)$ & $337(87.5 \%)$ & $190(90.0 \%)$ \\
\hline Works extended hours during weekend & $1378(80.2 \%)$ & $504(78.4 \%)$ & $393(81.9 \%)$ & $314(81.6 \%)$ & $167(79.2 \%)$ \\
\hline Works extended hours with team & $987(57.4 \%)$ & $363(56.4 \%)$ & $273(56.9 \%)$ & $229(59.5 \%)$ & $122(57.8 \%)$ \\
\hline
\end{tabular}

\section{Analyses}

Odds ratios (ORs) were estimated using mixed-effects logistic regression models on respondents having observed data for all covariates of interest. All models were adjusted for the following: team staffing (team staffed to the 3:1 ratio, working on multiple tams, turnover on the team) and clinic workload variables (panel overcapacity, average panel comorbidity, working extended hours), respondent occupation, duration of VA tenure, VA medical center (vs. CBOC) indicator, and two random intercepts for team and clinic, since respondents were nested within teams, which were further nested within clinics. Models that further estimated ORs by occupation (and other variables) included additional two- and three-way interaction terms between occupation and each of the variables of interest. As a sensitivity analysis, we re-estimated ORs using weighted propensity score methods to adjust for the potential selection bias often associated with low survey response. The propensity to respond was estimated for each responder and nonresponder using available administrative data (occupation, VA tenure, and clinic location); these propensities were used to form adjustment cells, and respondents were weighted by the inverse of the observed response rate in that cell, referred to as "response propensity stratification" ${ }^{34}$ (see Appendix A, available online).

\section{RESULTS}

A total of 4610 respondents were included in the sample ( $20.9 \%$ response rate). Of the 8114 teams in the administrative files at the time, $3020(37.2 \%)$ had at least one survey respondent and 1113 (13.7\%) had multiple respondents, and 702 of the 935 primary care clinics $(75.1 \%)$ had at least one respondent and $576(61.6 \%)$ had multiple respondents.

Overall, $40.8 \%$ of respondents screened positive for burnout, ranging from $32.0 \%$ of clinical associates to $49.2 \%$ of PCPs (Table 1). For staffing, $64.8 \%$ of respondents reported working on a team staffed to the recommended ratio, and $61.2 \%$ reported a change in one or more team members in the past 12 months. For workload, $31.6 \%$ of panels exceeded capacity when adjusted for panel size and part time versus full time; $37.3 \%$ worked extended hours during the week or weekend. Of those working extended hours, 57.4\% reported working at least $80 \%$ of extended hours with members of their own team versus other teams.

In unadjusted analyses, the largest burnout differences were between respondents on fully staffed versus not fully staffed teams ( $35.2 \%$ vs. $52.3 \%$, respectively), respondents with turnover versus no turnover on the teamlet $(45.7 \%$ vs. $33.2 \%$, respectively), and respondents with panel overcapacity versus no overcapacity (43.9\% vs. $39.9 \%$ ) (Table 2$)$. Although 
Table 2 Burnout Percentage by Provider Occupation, Team Staffing, and Clinic Workload

\begin{tabular}{|c|c|c|c|c|c|}
\hline \multirow[t]{2}{*}{ Variable } & \multicolumn{5}{|l|}{ Burnout \% (n) } \\
\hline & All roles $(n=4610)$ & $\mathrm{PCP}(n=1517)$ & Nurses $(n=1276)$ & $\mathrm{CA}(n=1164)$ & $\mathrm{AC}(n=653)$ \\
\hline \multicolumn{6}{|l|}{ Fully staffed, $\%(n)^{*}$} \\
\hline Yes $(n=2740)$ & $35.2 \%(964)$ & $43.8 \%(343)$ & $36.8 \%(276)$ & $26.4 \%$ (199) & $32.2 \%(146)$ \\
\hline No $(n=1485)$ & $52.3 \%(777)$ & $57.4 \%(329)$ & $50.9 \%(230)$ & $45.8 \%(151)$ & $51.5 \%(67)$ \\
\hline \multicolumn{6}{|l|}{ Turnover, \% $(n)$} \\
\hline Yes $(n=2821)$ & $45.7 \%(1288)$ & $53.6 \%(503)$ & $46.4 \%(384)$ & $36.3 \%(248)$ & $41.4 \%(153)$ \\
\hline No $(n=1789)$ & $33.2 \%(594)$ & $42.2 \%(244)$ & $32.6 \%(146)$ & $25.8 \%(124)$ & $28.3 \%(80)$ \\
\hline \multicolumn{6}{|c|}{ Member of multiple teams, $\%(n)$} \\
\hline Yes $(n=1241)$ & $42.2 \%(524)$ & $43.9 \%(93)$ & $46.8 \%(196)$ & $37.6 \%(123)$ & $39.6 \%(112)$ \\
\hline No $(n=3369)$ & $40.3 \%(1358)$ & $50.1 \%(654)$ & $39.0 \%(334)$ & $29.7 \%(249)$ & $32.7 \%(121)$ \\
\hline \multicolumn{6}{|l|}{ Panel overcapacity, $\%(n)^{\dagger}$} \\
\hline Yes $(n=1371)$ & $43.9 \%(602)$ & $53.3 \%(251)$ & $43.2 \%(153)$ & $37.0 \%(136)$ & $34.8 \%(62)$ \\
\hline No $(n=2963)$ & $39.9 \%(1181)$ & $48.0 \%(455)$ & $41.1 \%(346)$ & $29.5 \%(217)$ & $37.1 \%(163)$ \\
\hline \multicolumn{6}{|c|}{ Average panel comorbidity, \% $(n)^{*}$} \\
\hline Category $4(n=1143)^{\S}$ & $41.6 \%(475)$ & $48.0 \%(209)$ & $42.6 \%(127)$ & $33.3 \%(86)$ & $34.9 \%(53)$ \\
\hline Category $3(n=1144)$ & $40.0 \%(458)$ & $48.0 \%(181)$ & $41.9 \%(135)$ & $31.9 \%(89)$ & $31.9 \%(53)$ \\
\hline Category $2(n=1144)$ & $44.2 \%(506)$ & $54.8 \%(199)$ & $43.5 \%(135)$ & $36.1 \%(113)$ & $37.3 \%(59)$ \\
\hline Category $1(n=1143)$ & $37.3 \%(426)$ & $45.8 \%(154)$ & $37.8 \%(124)$ & $26.5 \%(82)$ & $38.8 \%(66)$ \\
\hline \multicolumn{6}{|c|}{ Works extended hours, \% ( $n)$} \\
\hline Yes $(n=1719)$ & $44.0 \%(756)$ & $51.9 \%(334)$ & $42.5 \%(204)$ & $34.8 \%(134)$ & $39.8 \%(84)$ \\
\hline No $(n=2891)$ & $38.9 \%(1126)$ & $47.3 \%(413)$ & $41.0 \%(326)$ & $30.6 \%(238)$ & $33.7 \%(149)$ \\
\hline \multicolumn{6}{|c|}{ Burnout $\%(n)$ among the subgroup that work extended hours $N=1719$} \\
\hline & All roles $(n=1719)$ & $\mathrm{PCP}(n=643)$ & Nurses $(n=480)$ & $\mathrm{CA}(n=385)$ & $\mathrm{AC}(n=211)$ \\
\hline \multicolumn{6}{|l|}{ Clinic workload } \\
\hline \multicolumn{6}{|c|}{ Works extended hours during week } \\
\hline Yes $(n=1538)$ & $43.2 \%(664)$ & $51.5 \%(295)$ & $42.7 \%(187)$ & $32.0 \%(108)$ & $38.9 \%(74)$ \\
\hline No $(n=181)$ & $50.8 \%(92)$ & $55.7 \%(39)$ & $40.5 \%(17)$ & $54.2 \%(26)$ & $47.6 \%(10)$ \\
\hline \multicolumn{6}{|c|}{ Works extended hours during weekend } \\
\hline Yes $(n=1378)$ & $45.6 \%(628)$ & $53.4 \%(269)$ & $43.5 \%(171)$ & $38.2 \%(120)$ & $40.7 \%(68)$ \\
\hline No $(n=341)$ & $37.5 \%(128)$ & $46.8 \%(65)$ & $37.9 \%(33)$ & $19.7 \%(14)$ & $36.4 \%(16)$ \\
\hline \multicolumn{6}{|c|}{ Works extended hours with team } \\
\hline Yes $(n=987)$ & $40.6 \%(401)$ & $49.0 \%(178)$ & $38.5 \%(105)$ & $31.0 \%(71)$ & $38.5 \%(47)$ \\
\hline No $(n=732)$ & $48.5 \%(355)$ & $55.7 \%(156)$ & $47.8 \%(99)$ & $40.4 \%(63)$ & $41.6 \%(37)$ \\
\hline
\end{tabular}

*Fully staffed responses of "I don't know" are not included $(n=385)$

Panel overcapacity missing for 276 respondents

* Panel comorbidity missing for 36 respondents

${ }^{\S}$ Quartile 4 has the highest panel comorbidity

overall burnout prevalence differed by occupation and was highest among PCPs, differences in burnout by team staffing, turnover, and panel overcapacity status were similar for all four occupations (Table 2).

Respondents who reported working on teams that had appointments outside traditional business hours (i.e. "extended hours") had burnout prevalence of $44.0 \%$, versus $38.9 \%$ for respondents not working extended hours. Among team members working extended hours, those working extended hours during the week had burnout prevalence of $43.2 \%$, versus $50.8 \%$ for those who did not. Conversely, burnout prevalence was $45.6 \%$ for those working extended hours during the weekend, versus $37.5 \%$ for those not working extended hours during the weekend. Team members who worked extended hours with their teamlets had burnout prevalence of $40.6 \%$, versus $48.5 \%$ for those who did not work extended hours with their teamlet (Table 2).

In adjusted models, working on a fully staffed team $(\mathrm{OR}=$ $0.55,95 \%$ CI $0.47-0.65)$, turnover on the team $(\mathrm{OR}=1.67$, 95\% CI 1.43-1.94), and having panel overcapacity ( $\mathrm{OR}=1.19$, 95\% CI 1.01-1.40) were all significantly associated with odds of burnout (Table 3). Working on multiple teams, average panel comorbidity, and working extended hours were not associated with burnout. When testing the interactions between these variables and occupation, we found that these associations did not differ by occupation (results not displayed).
The associations between burnout, team staffing, team turnover, and panel capacity appear to be additive (Fig. 1). For example, observed burnout for respondents on a team that had no turnover, was fully staffed, and had a panel within capacity was $28.5 \%$, whereas that for respondents on a team not fully staffed, that had experienced turnover in the prior year, and that had panel overcapacity was $58.6 \%$.

Propensity score methods, described in Appendix A (available online), produced ORs for fully staffed, turnover, and overcapacity that remained significant and in the same direction as our original analysis. The propensity-weighted ORs for turnover and overcapacity were larger, and the OR for fully staffed smaller, than our original non-weighted results. The OR for being a member of multiple teams was statistically significant in the predicted direction in the propensity-weighted model only.

\section{DISCUSSION}

In this study of VA primary care employees working in PCMH teams, burnout was associated with several workload and staffing characteristics. Inadequate staffing, team member turnover, and patient panel overcapacity were all associated with burnout among all occupations within the team. The associations with burnout were statistically significant, large, and 
Table 3 Adjusted Odds of Burnout $(n=3986)$

\begin{tabular}{lll}
\hline \hline Variable & & Odds ratio (95\% CI) \\
\cline { 1 - 1 } PCP & & Ref \\
\hline Nurse & $0.71(0.59-0.85)$ \\
Clinical associate & $0.47(0.39-0.58)$ \\
Administrative clerk & $0.72(0.56-0.91)$ \\
Fully staffed & $0.55(0.47-0.65)$ \\
Turnover & $1.67(1.43-1.94)$ \\
Member of multiple teams & $1.13(0.95-1.34)$ \\
Panel overcapacity & $1.19(1.01-1.40)$ \\
Average panel comorbidity & $1.12(0.84-1.48)$ \\
Works extended hours & $1.14(0.96-1.34)$ \\
Odds ratio $(95 \%$ CI) among the $N=1514$ & that work extended hours \\
Works extended hours during week & $0.76(0.51-1.12)$ \\
Works extended hours during weekend & $1.48(1.06-2.05)$ \\
Works extended hours with team & $0.74(0.58-0.95)$ \\
\hline
\end{tabular}

additive. Observed burnout for employees on a fully staffed team with no turnover and a panel within capacity was an absolute $30.1 \%$ lower than that for employees on understaffed teams, with turnover, and with patient panel overcapacity.

An important finding from this paper is that, while the overall prevalence of burnout was lower for nurse care managers, clinical associates, and administrative clerks relative to PCPs, the associations with workload and staffing variables did not differ significantly by occupation. Prior literature has rarely included team members such as clinical associates or clerks.

Among those with patient appointments outside traditional business hours, working extended hours on the weekend, but not during the week, was associated with higher burnout, something for clinics to consider when assessing options to provide more convenient hours of operation for patients. Working extended hours with one's team was associated with lower odds of burnout, which is consistent with the supposition that team-based primary care is a more supportive work environment and may reduce burnout. Alternatively, clinics able to schedule teams to work extended hours together may be different in other ways not captured in the model, such as how well the clinic is managed and overall staffing availability (as opposed to team-specific staffing). Those factors may be associated with lower burnout and may be unobserved confounders. In addition, there are ways that PCPs and staff work outside regular business hours, such as charting and responding to patient messages, that we do not capture with this item. These may be important correlates of burnout as well.

We found no association between burnout and working on multiple teams, working extended hours during the week, clinic location (hospital- vs. community-based), or patient panel complexity.

These findings make several contributions to the current literature on burnout and team-based primary care. We linked individual survey data on burnout to team-level administrative data on panel size and average patient complexity, whereas previous studies in primary care settings have relied on selfreported workload, ${ }^{20,22,35}$ which introduces the risk of method bias. ${ }^{36}$ Examining clinic-level rather than team-level

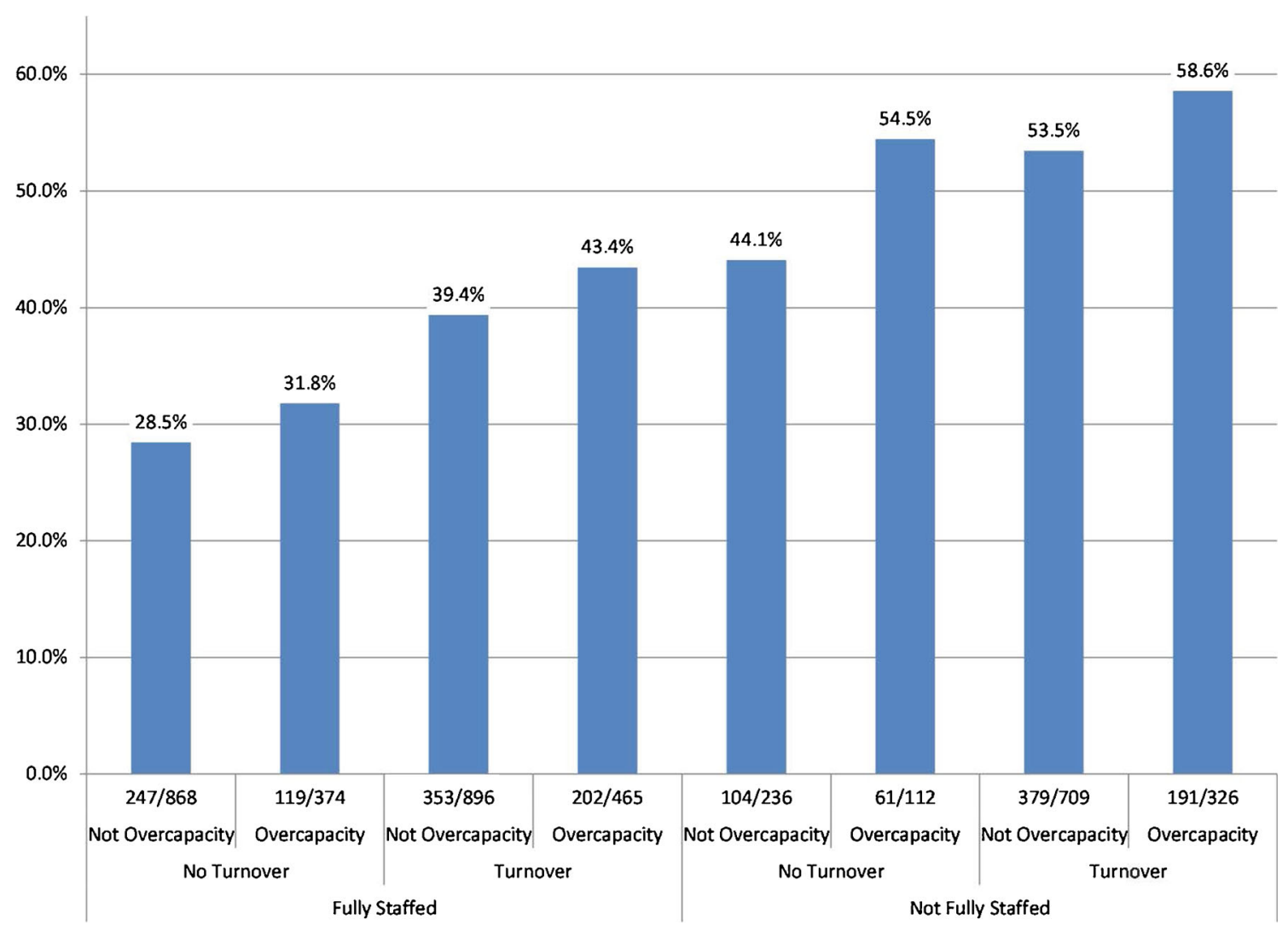

Figure 1 Observed burnout percentages by combinations of team staffing, team turnover, and panel overcapacity. 
patient complexity and panel size may mask important variations among teams, and may explain why a previous analysis observed no association between clinics with average panel size overcapacity and burnout among their employees. ${ }^{29}$

Our findings highlight the potential importance of stable team membership and adequate staffing. A recent study of 29 high-performing primary care practices using team-based care models identified stable team structure and adequate staffing ratios as among the nine key success factors. ${ }^{37}$ Finally, while most of the literature on burnout in primary care has focused on physicians and $\mathrm{RNs},{ }^{18-22,} 35$ our findings also include other members of the primary care team including LPNs, medical technicians, and administrative clerks, and we found similar patterns of associations among these members of the primary care team.

\section{Limitations}

The most important limitation of this study is potential response bias, with an estimated response rate of $21 \%$ for primary care personnel. When we compared respondents to non-respondents using administrative data, we found that nonresponse was associated with occupation, VA tenure, and clinic location, with lower response rates for administrative clerks, those with longer VA tenure, and those at VA medical center-based clinics (as opposed to community-based clinics). Consequently, we adjusted for these three variables in all complete-case regression models, since regression coefficients are not subject to response bias if the probability of nonresponse depends only on observed variables accounted for in the regression. ${ }^{38}$ As an additional sensitivity analysis, we used propensity score models to examine the effect of nonresponse on our initial findings, and found that model coefficients remained significant and in the same direction, but with more extreme ORs. While we cannot rule out the possibility that unobserved differences between respondents and nonrespondents affected the results, the propensity score results suggest that our initial findings may be conservative.

These findings do not demonstrate causality. These were cross-sectional analyses, focused on a relatively small set of workplace variables and testing a relatively limited set of associations. Burnout is highly complex and is likely a function of interactions among a range of variables, including relationships with patients, clinician social support, and innate resilience. These findings are influenced both by unobserved confounders, such as the quality of the clinic leadership, and imperfect measurement, such as an inability to distinguish between turnover when a poor performer leaves and that from failure to retain a needed team member.

VA primary care settings differ from other primary care settings in ways that may limit the generalizability of the findings, such as lower average panel sizes, higher patient comorbidities, longer visit times, and a salaried structure with a quality metric-based performance system. ${ }^{39}$
Finally, there are concerns about endogeneity. Burnout is a known precursor to turnover, and the conditions that lead to burnout likely affect the primary care team broadly. Therefore, turnover on the teamlet might be as much a consequence of burnout as a cause.

\section{CONCLUSIONS}

We found large differences in burnout associated with team staffing, team member turnover, and patient panel capacity. Previous studies have found higher burnout associated with working overtime ${ }^{18,19}$ and having insufficient clinical staff to manage workloads, ${ }^{23-26}$ and lower burnout associated with working in a team structure with a strong team culture ${ }^{40}$ and the quality of physician-nurse relationships. ${ }^{24}$ Our findings make an important contribution by testing these associations at the team level and for all team members. Whereas most prior research is based on self-reported workload, we linked burnout to independent measures of team-level workload from administrative data. We also assessed burnout among all members of the medical home team, including clinical associates, and administrative clerks, whereas with few exceptions, ${ }^{40}$ prior research has focused exclusively on physicians and RNs. Overall, our findings confirm the importance of team stability and the completeness of team staffing as critical factors in predicting burnout levels among primary care physicians, nurses, and administrative staff. Future research is needed to determine whether burnout declines as staffing and workload improve.

\section{Acknowledgements:}

This work was supported by the Patient Centered Medical Home Demonstration Laboratory Coordination Center (XVA-61-041) of the U.S. Department of Veterans Affairs. The survey was conducted by the VA Healthcare Analysis and Information Group, and we are grateful to Tanya Kotar and Julie Kurutz for their exceptional work leading the survey. The contents do not represent the views of the U.S. Department of Veterans Affairs or the United States government.

Author contributions: $C D H, J A S$, and GBW are members of an evaluation workgroup that helped develop the survey, and planned and oversaw analyses. WLC conducted the analyses, and LT was the consulting statistician. GS and RS are leaders of the national PACT initiative, and LVR, SDF, and KMN are leaders of the PACT evaluation that sponsored the survey, and guided survey content and analysis aims. CDH drafted the manuscript. All authors critically reviewed and contributed to the manuscript, and approved the final submission.

Corresponding Author: Christian D. Helfrich, MPH, PhD; SeattleDenver Center of Innovation for Veteran-Centered and Value-Driven Care VA Puget Sound Puget Sound Health Care SystemUS Department of Veterans Affairs, Seattle, WA, USA (e-mail: christian. helfrich@va.gov).

\section{Compliance with Ethical Standards:}

Conflict of Interest: The authors declare that they do not have a conflict of interest. 


\section{REFERENCES}

1. Maslach C, Schaufeli WB, Leiter MP. Job burnout. Annu Rev Psychol. 2001;52(1):397-422.

2. Shanafelt TD, Hasan O, Dyrbye LN, Sinsky C, Satele D, Sloan J, West CP. Changes in burnout and satisfaction with work-life balance in physicians and the general US working population between 2011 and 2014. In Mayo Clinic Proceedings (Vol. 90, No. 12, pp. 1600-1613) (2015, December). Elsevier.

3. Shanafelt TD, Boone S, Tan L, et al. Burnout and satisfaction with work-life balance among US physicians relative to the general US population. Arch Intern Med. 2012;172(18):1377-1385.

4. Aiken LH, Clarke SP, Sloane DM, et al. Nurses' Reports On Hospital Care In Five Countries. Health Aff. 2001;20(3):43-53.

5. Simonetti J, Sylling PW, Nelson K, et al. Patient-Centered Medical Home Implementation and Burnout among VA Primary Care Employees. J Ambul Care Manage. 2016.

6. Vahey DC, Aiken LH, Sloane DM, Clarke SP, Vargas D. Nurse burnout and patient satisfaction. Med Care. 2004;42(2 Suppl):Ii57-66.

7. Argentero P, Dell'Olivo B, Ferretti MS. Staff burnout and patient satisfaction with the quality of dialysis care. Am J Kidney Dis. 2008;51(1):80-92.

8. Shanafelt TD, Bradley KA, Wipf JE, Back AL. Burnout and selfreported patient care in an internal medicine residency program. Ann Intern Med. 2002;136(5):358-367.

9. West CP, Tan AD, Habermann TM, Sloan JA, Shanafelt TD. Association of resident fatigue and distress with perceived medical errors. JAMA. 2009;302(12): 1294-1300.

10. Cimiotti JP, Aiken LH, Sloane DM, Wu ES. Nurse staffing, burnout, and health care-associated infection. Am J Infect Control. 2012;40(6):486-490.

11. Shanafelt TD, Raymond M, Kosty M, et al. Satisfaction with work-life balance and the career and retirement plans of US oncologists. J Clin Oncol: Off J Am Soc Clin Oncol. 2014;32(11):1127-1135.

12. Linzer M, Manwell LB, Williams ES, et al. Working conditions in primary care: physician reactions and care quality. Ann Intern Med. 2009;151(1):28-36. W26-29.

13. Parker PA, Kulik JA. Burnout, self- and supervisor-rated job performance, and absenteeism among nurses. J Behav Med. 1995;18(6):581599.

14. Shanafelt TD, Mungo M, Schmitgen J, et al. Longitudinal study evaluating the association between physician burnout and changes in professional work effort. Paper presented at: Mayo Clinic Proceedings2016.

15. Landon BE, Reschovsky JD, Pham HH, Blumenthal D. Leaving medicine: the consequences of physician dissatisfaction. Med Care. 2006;44(3):234-242.

16. Shanafelt T, Sloan J, Satele D, Balch C. Why do surgeons consider leaving practice? J Am Coll Surg. 2011;212(3):421-422.

17. Bodenheimer T, Sinsky C. From triple to quadruple aim: care of the patient requires care of the provider. Ann Family Med. 2014;12(6):573576.

18. Garrett C. The Effect of Nurse Staffing Patterns on Medical Errors and Nurse Burnout. AORN J. 2008;87(6):1191-1204

19. Van Ham I, Verhoeven AAH, Groenier KH, Groothoff JW, De Haan J. Job satisfaction among general practitioners: A systematic literature review. Eur J Gen Pract. 2006; 12(4):174-180.
20. Deckard G, Meterko M, Field D. Physician burnout: an examination of personal, professional, and organizational relationships. Med Care. 1994:745-754.

21. Linzer M, Konrad TR, Douglas J, et al. Managed Care, Time Pressure, and Physician Job Satisfaction: Results from the Physician Worklife Study. J Gen Intern Med. 2000;15(7):441-450.

22. Linzer M, Manwell L, Williams E, et al. Working conditions in primary care: physician reactions and care quality. Ann Intern Med. 2009;151(1):28.

23. Mijakoski D, Karadzinska-Bislimovska J, Basarovska V, et al. Burnout, Engagement, and Organizational Culture: Differences between Physicians and Nurses..2015.

24. Leiter MP, Laschinger HKS. Relationships of work and practice environment to professional burnout: testing a causal model. Nurs Res. 2006;55(2): 137-146.

25. Pearson A, Pallas LOB, Thomson D, et al. Systematic review of evidence on the impact of nursing workload and staffing on establishing healthy work environments. Int J Evid Based Healthc. 2006;4(4):337-384.

26. McVicar A. Workplace stress in nursing: a literature review. J Adv Nurs. 2003;44(6):633-642.

27. Bodenheimer T, Laing BY. The teamlet model of primary care. Ann Fam Med. 2007;5(5):457-461.

28. Klein S. The Veterans Health Administration: Implementing PatientCentered Medical Homes in the Nation's Largest Integrated Delivery System. Commonw Fund Publ. 2011;1537:16.

29. Helfrich CD, Dolan ED, Simonetti J, et al. Elements of team-based care in a patient-centered medical home are associated with lower burnout among VA primary care employees. J Gen Intern Med. 2014;29(Suppl 2):S659-666

30. Simonetti J, Sylling PW, Nelson K, et al. Patient-Centered Medical Home Implementation and Burnout among VA Primary Care Employees. Ann Int Med. Under review.

31. Ladebue AC, Helfrich CD, Gerdes ZT, Fihn SD, Nelson KM, Sayre GG. The experience of Patient Aligned Care Team (PACT) members. Health Care Manag Rev. 2014.

32. Dolan E, Mohr D, Lempa M, et al. Using a Single Item to Measure Burnout in Primary Care Staff: A Psychometric Evaluation. J Gen Intern Med. 2014;30(5):582-587.

33. Gagne JJ, Glynn RJ, Avorn J, Levin R, Schneeweiss S. A combined comorbidity score predicted mortality in elderly patients better than existing scores. J Clin Epidemiol. 2011;64(7):749-759.

34. Little RJ. Survey nonresponse adjustments. Int Stat Rev. 1986;54(1):3.

35. Gregory ST, Menser T. Burnout among primary care physicians: A test of the Areas of Worklife model. J Healthc Manag. 2015;60(2):133-148.

36. Podsakoff $\mathbf{P}$, Mackenzie $\mathbf{S}$, Lee $\mathbf{J}$, Podsakoff $\mathbf{N}$. Common method biases in behavioral research: A critical review of the literature and recommended remedies. J Appl Psychol. 2003;88(5):879.

37. Ghorob A, Bodenheimer T. Building teams in primary care: A practical guide. Families, Systems, \& Health. 2015;33(3):182.

38. Little RJA, Rubin DB. Statistical Analysis with Missing Data, Second Edition. John Wiley \& Sons, Inc.; 2014.

39. Kizer KW. The "new VA": a national laboratory for health care quality management. Am J Med Qual. 1999;14(1):3-20.

40. Willard-Grace R, Hessler D, Rogers E, Dubé K, Bodenheimer T, Grumbach K. Team Structure and Culture Are Associated With Lower Burnout in Primary Care. J Am Board Family Med. 2014;27(2):229-238. 